\title{
BAKING QUALITY PREDICTION OF SPELT WHEAT BASED ON RHEOLOGICAL AND MIXOLAB PARAMETERS
}

\author{
M. Lacko-Bartošováa* , P. Konvalina ${ }^{\mathrm{b}}$ and L. Lacko-BartošovÁa \\ ${ }^{a}$ Department of Sustainable Agriculture and Herbology, Faculty of Agrobiology and Food Resources, Slovak \\ University of Agriculture in Nitra, Tr. A. Hlinku 2, 94976 Nitra. Slovakia \\ ${ }^{b}$ Department of Agroecosystems, Faculty of Agriculture, University of South Bohemia in České Budějovice, \\ Branišovská 1645/31a, 37005 České Budějovice. Czech Republic \\ 'Department of Applied Informatics and Computing Technology, Faculty of National Economy, University of \\ Economics in Bratislava, Dolnozemská cesta 1, 85235 Bratislava. Slovakia
}

(Received: 16 June 2018; accepted: 8 January 2019)

The aim of this work was to test the potential of Mixolab II in the baking quality prediction of five Triticum spelta L. cultivars grown during growing periods with different climate conditions. Spelt cultivars varied in flour and dough properties examined by indirect baking quality indicators (wet gluten content, Falling number, Zeleny sedimentation, farinograph rheological properties, Mixolab parameters) and direct baking test, strong effect of climatic conditions was determined. Results showed significant differences in protein and starch - amylase part of Mixolab II curve, indicating the genotype and climatic effect. Spelt cultivars were characterised by high protein weakening $(\mathrm{C} 2=0.32 \mathrm{Nm})$, speed of protein network weakening at the level of $\alpha=-0.07 \mathrm{Nm} \mathrm{min}^{-1}$, starch gelatinisation $(C 3=1.61 \mathrm{Nm})$, amylolytic activity $(C 4=1.35 \mathrm{Nm})$, and starch retrogradation $(C 5=1.98 \mathrm{Nm})$. Significant correlations between indirect baking properties, farinograph and Mixolab II parameters, and direct baking test were found. Slope $\alpha$ of Mixolab curve was a promising parameter in estimation of direct baking parameter - specific bread volume, together with indirect indicator - Zeleny sedimentation.

Keywords: Triticum spelta L., Mixolab, grain and flour quality, baking quality prediction

The increasing demand for nutritionally healthy food products, the asserted therapeutic properties of foodstuff, the need for crop diversification have led to a renewed interest in ancient wheats such as einkorn, emmer, or spelt (ARZANi \& Ashraf, 2017). The study of BÉKÉS and co-workers (2017) summarizes the up-to-date knowledge on cereals-related health disorders and highlights the potential of developing "healthier" spelt-based cereal products.

Spelt grain has high nutritional value, but the rheological properties of dough made from spelt flour remain insufficiently investigated (WIWART et al., 2017). The bread making quality of wheats can be evaluated by various quality tests. The evaluation of flour and dough characteristics can be conducted using traditional rheological instruments such as Farinograph, Extensograph, Alveograph, and others. The most reliable method is direct baking test, however, it is time-consuming, requires skilled personnel, and is difficult to use for commercial purposes. Therefore, other quick methods are needed to test the suitability of

\footnotetext{
* To whom correspondence should be addressed.

Phone: +421 37641 4205; e-mail: magdalena.lacko-bartosova@uniag.sk
}

This is an open-access article distributed under the terms of the Creative Commons Attribution-NonCommercial 4.0 International License (https://creativecommons.org/licenses/by-nc/4.0/), which permits unrestricted use, distribution, and reproduction in any medium for non-commercial purposes, provided the original author and source are credited, a link to the CC License is provided, and changes - if any - are indicated. 
flours in terms of baking quality (KoKsel et al., 2009). A new rheological device - Mixolab has been developed that enables to describe the dough consistency during heating and cooling period. The apparatus measures both flour protein and starch characteristics and provides information about protein breakdown, starch gelatinisation, enzyme activity, and gel strength in a single test (DuBAT, 2010). Mixolab was used for e.g. to predict the cookie and cake quality (KAHRAMAN et al., 2008; OzTURK et al., 2008), the effects of antioxidants on dough mixing properties (ABDEL-SAMIE et al., 2010), the effect of linseed fibre on wheat flour pasting, dough properties, and bread quality (ŠvEC \& HRUŠKOVÁ, 2018), etc.

The information related to Mixolab utilization on different aspects of hulled wheats' flour quality, influencing the quality of finished products, are limited.

The objectives of presented study were to evaluate the Triticum spelta L. cultivar on their properties related to technological grain, flour, and direct baking quality, to test the potential of Mixolab in the quality evaluation, to examine the relations between technological quality parameters, Mixolab parameters, and baking test for the prediction of spelt bread making quality, and finally to evaluate the influence of environmental conditions on the parameters under study.

\section{Materials and methods}

\subsection{Field trials and experimental design}

Field experiments were carried out at the Slovak University of Agriculture in Nitra - SUA $\left(48^{\circ} 19^{\prime} \mathrm{N}, 18^{\circ} 07^{\prime} \mathrm{E}\right)$ as randomised - block experiment, in four replicates. The elevation of the experimental area is $177-178$ meters above sea level, with continental climate, belongs to warm agro-climatic region, arid subregion with predominantly mild winter with average long-term (1961-1990) annual precipitations of $532.5 \mathrm{~mm}$. Winter spelt wheat varieties were cultivated under the ecological farming conditions, within the crop rotation: common pea, spelt, spring barley. The experimental material comprised 5 winter pure spelt varieties (Altgold, Ostro, Oberkulmer Rotkorn - Swiss varieties, Ebners Rotkorn - Austrian, Rubiota - Czech variety). Grain and flour qualitative traits were analysed during two consecutive growing periods (2014-2015).

\subsection{Quality traits}

Indirect baking quality indicators were determined in four replicates. Wet gluten $\left(\mathrm{G}_{\mathrm{tot}}\right)$ was analysed by Glutomatic 2200 (Perten Instruments, Sweden) according to the ICC 155 method. Sedimentation value (Zeleny in $\mathrm{ml}, \mathrm{ZT}$ ) was determined using Shaker - Type SDZT4 apparatus (Santec, Slovakia) in accordance with ICC 116/1.

The rheological properties of dough were assessed using Brabender Farinograph (Brabender, Germany), to determine the dough development time in minutes (DDT), stability of dough in minutes (DS), and dough softening after 12 min in FU (SD).

Baking test was performed according to the ICC 131 method at the water level of Farinograph absorption with some modifications, with the baking formula: flour ( $600 \mathrm{~g}, 14 \%$ moisture basis), compressed yeast (9.46 g), salt (7.89 g), and sugar (9.78 g). Doughs were mixed for $3 \mathrm{~min}$ in KitchenAid 5KSM 150 equipment (KitchenAid, USA), left to rise for 30 min in fermentation chamber. The dough was punched, moulded, put into a baking pan, and left for fermentation for another $90 \mathrm{~min}$. Doughs were baked for $20 \mathrm{~min}$ at $225^{\circ} \mathrm{C}$ (UNOX 
XF 195, Italy). Baking tests were performed in triplicate. Bread volume was determined by the rapeseed displacement method (AACCI 10-05.01) using volumeter OBK (Mezos, Czech Republic) and specific loaf volume (SLV) was calculated.

Dough mixing and pasting behaviours were analysed in flour using the Mixolab II (CHOPIN Technologies, France), according to the AACC International Method 54-60.01 (DuBAT, 2010). The parameters evaluated at Mixolab curve:

Torque $\mathrm{C} 1$ - maximum point of the first mixing phase

Torque $\mathrm{C} 2$ - end point of the phase 2, protein weakening

Torque $\mathrm{C} 3$ - end point of the phase 3 , the rate of starch gelatinisation

Torque $\mathrm{C} 4$ - end point of the phase 4 , amylolytic activity and hot gel stability

Torque $\mathrm{C} 5$ - end point of the phase 5 , starch retrogradation in the cooling phase

$\mathrm{C} 3-\mathrm{C} 4-$ shows amylase activity and is linked to Falling number

Slope $\alpha$-between end of $30^{\circ} \mathrm{C}$ period and $\mathrm{C} 2$ - speed of the protein weakening under heating effect

Slope $\beta$ - between $\mathrm{C} 2$ and $\mathrm{C} 3$, indicator of pasting (gelatinisation) speed

Slope $\gamma$ - between C3 and C4, enzymatic ( $\alpha$-amylase) degradation speed

\subsection{Statistical analysis}

Collected data were subjected to multifactorial analysis of variance, significant differences between factors were determined by $\mathrm{F}$-test at $* \mathrm{P}<0.05, * * \mathrm{P}<0.01$, and $* * * \mathrm{P}<0.001$ probability levels. When significant, it was followed by Fisher's least significant difference test at $\mathrm{P}<0.05$, to identify significantly different means. Correlation analysis were applied in order to evaluate the strength of the correlation between the parameters under study at a significance level of $\mathrm{P}<0.01$. The statistical analyses were performed with the software STATISTICA version 10.0 (StatSoft, USA).

\section{Results and discussion}

Indirect parameters used for evaluation of the quality and baking value of flour are gluten content and its quality. Total gluten content $\left(\mathrm{G}_{\text {tot }}\right)$, Zeleny sedimentation (ZT) mean values of spelt cultivars were $35.18-40.38 \%$ and $19.50-28.17 \mathrm{ml}$, respectively (Table 1), with significant differences between cultivars, growing years, and their interaction. Influence of climate conditions was recorded; in 2015, lower precipitations and higher temperature during grain filling resulted in significantly higher $\mathrm{G}_{\text {tot }}$ and ZT. The highest $\mathrm{G}_{\text {tot }}$ of all tested wheat species (Tr. aestivum, durum, spelta, dicoccum) reported by RACHOŃ and co-workers (2016) was found for spelt, but low gluten index (25) indicated that spelt was weak for bread production.

Farinograph rheological properties such as dough development time (DDT), dough stability (DS), and softening of dough (SD) confirmed great differences among cultivars, which exhibited the characteristics of weak to strong flour, with significant influence of environmental conditions, cultivars, and their interaction. Higher values of SD indicate that dough will not be able to sustain long mechanical processing treatments. Strong wheat is characterised with longer DDT and higher DS. Spelt cultivars used in this study varied in flour and dough properties, therefore bread produced differed in the specific loaf volume (SLV), ranging from $372.07 \mathrm{~cm}^{3} / 100 \mathrm{~g}$ to $434.03 \mathrm{~cm}^{3} / 100 \mathrm{~g}$. The best rheological properties were determined for modern cultivar Rubiota, with the highest values of DDT, DS and lowest 


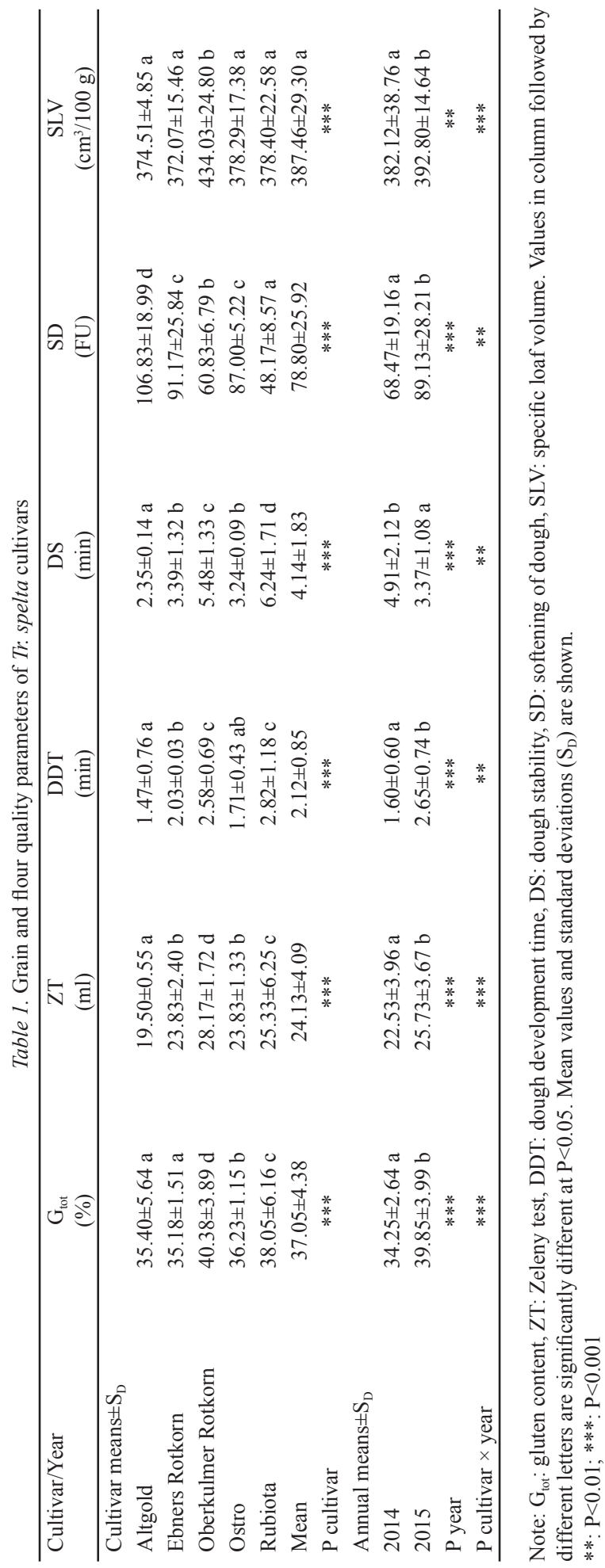


SD, but the highest SLV was achieved by cultivar Oberkulmer Rotkorn, with the best ZT and second best parameters of DS and SD. SCHOBER and co-workers (2002) pointed out the relationship between baking results and gluten properties of 27 European spelt cultivars, great diversity within spelt material, but also similarities between several cultivars were determined. Differences between Tr. spelta technological properties of grain and flour and common wheat were confirmed by BoDrožA-SOLAROV and co-workers (2009) and KonvalinA and co-workers (2014) in higher gluten (30.2-54.4\%), higher protein content (12.37-19.4\%), but lower Gluten index (4.0-52\%), high variability in ZT (18.9-35 ml), which indicates differences in terms of bread making quality.

The Mixolab process has the advantage of being able to measure properties of proteins, starch, and associated enzymes in one test. The Mixolab results are summarised in Table 2 and in Figure 1. At the beginning of heating, decrease in dough consistency is the result of protein weakening. The greater the decrease in consistency, the lower the protein quality (SCHMiele et al., 2017). C2 values were significantly affected by cultivar, growing year, and their interactions. The mean $\mathrm{C} 2$ value was $0.32 \mathrm{Nm}$, the highest value was recorded for Rubiota $(0.39 \mathrm{Nm})$. C2 values below $0.4 \mathrm{Nm}$ indicates that dough from this wheat species can be less tolerant to mixing. Good quality proteins are represented by $\mathrm{C} 20.5-0.6 \mathrm{Nm}$. The difference $\mathrm{C} 1-\mathrm{C} 2$ was significant for all factors and interaction, averaging $0.78 \mathrm{Nm}$, the lowest value, indicating stronger gluten properties, was determined for Rubiota. In the study of WIWART and co-workers (2017), C2 values for pure spelt cultivars were $0.4 \mathrm{Nm}$, which suggests that the resulting dough is less tolerant to mixing. Slope $\alpha$, as an indicator of the speed of the protein network weakening due to the effects of heat, varied from $-0.04 \mathrm{Nm} \mathrm{min}^{-1}$ to $-0.11 \mathrm{Nm} \mathrm{min}^{-1}$, the factor cultivar was significant with lowest value for Rubiota cultivar.

Starch properties such as gelatinisation (C3), amylolytic activity (C4), and starch retrogradation (C5), determined by Mixolab II, were significantly influenced by both experimental factors. Maximum value of torque in the heating phase $\mathrm{C} 3$ averaged $1.62 \mathrm{Nm}$ and was the highest for Rubiota, indicating higher starch gelatinisation temperature and higher dough viscosity. Stability of the hot paste in the test, phase C4 - when consistency decreases as a result of amylolytic activity, was the highest for Rubiota and Ostro (1.51 Nm). Difference between $\mathrm{C} 3$ and $\mathrm{C} 4$, the stability of the starch gel when heated, was not influenced by experimental factors. Higher torque in the phase $\mathrm{C} 5$, a measure of retrogradation of starch molecules in the dough during cooling stage of cultivars Rubiota and Altgold indicates lower amylolytic activities of these cultivars.

Correlations were determined between Mixolab parameters and bread quality parameters to identify those Mixolab parameters, which can demonstrate the suitability for estimating bread making quality (Table S1). Strong correlation was found between Farinograph DS and $\mathrm{C} 2(\mathrm{r}=0.69)$, medium strong between DS and C3 $(\mathrm{r}=0.62)$ and DS and C5 $(\mathrm{r}=-0.60)$. Medium strong correlations were determined for SD and C2, C3, and C5 (negative). The only Mixolab parameter strongly correlated with specific loaf volume was slope $\alpha(\mathrm{r}=-0.71)$, showing the importance of protein weakening speed in bread volume. Medium strong correlation between C5 and SLV indicated the role of starch phase - retrogradation and amylolytic activity for bread making quality. The promising parameter for direct baking quality of spelt is ZT, strong correlation with SLV ( $\mathrm{r}=0.75$ ) was found. The rheological properties of spelt dough, analysed by Mixolab test, and their relation to other indirect and direct baking quality indicators have not yet been sufficiently investigated and reported in the scientific literature. By other researchers, different results are reported, depending on cereal species, cultivars, pedo- 


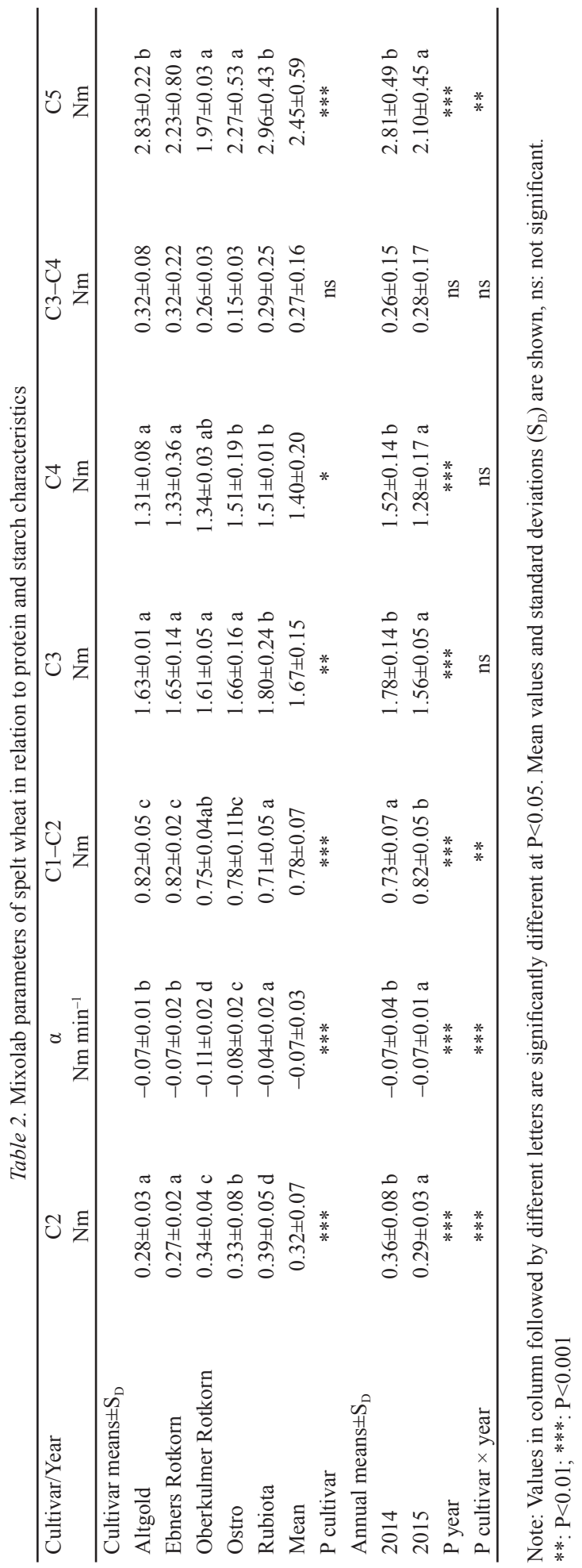


climatic conditions, intensity of technology, etc. RAchoN and co-workers (2016) found correlations between Cs, difference Cs-C2 and $\mathrm{G}_{\mathrm{tot}}$, DHAKA and co-workers (2012) between C2 and SLV for common wheat. In the work of WIWART and co-workers (2017), the difference Cs-C2 was more strongly correlated with spelt protein content $(r=0.79)$ than other Mixolab parameters. KYPTOVA and co-workers (2017) reported noticeably slower starch gelatinisation speed of spelt wheat than common wheat and lower slope $\gamma$, therefore spelt dough requires shorter time of baking and lower temperature.

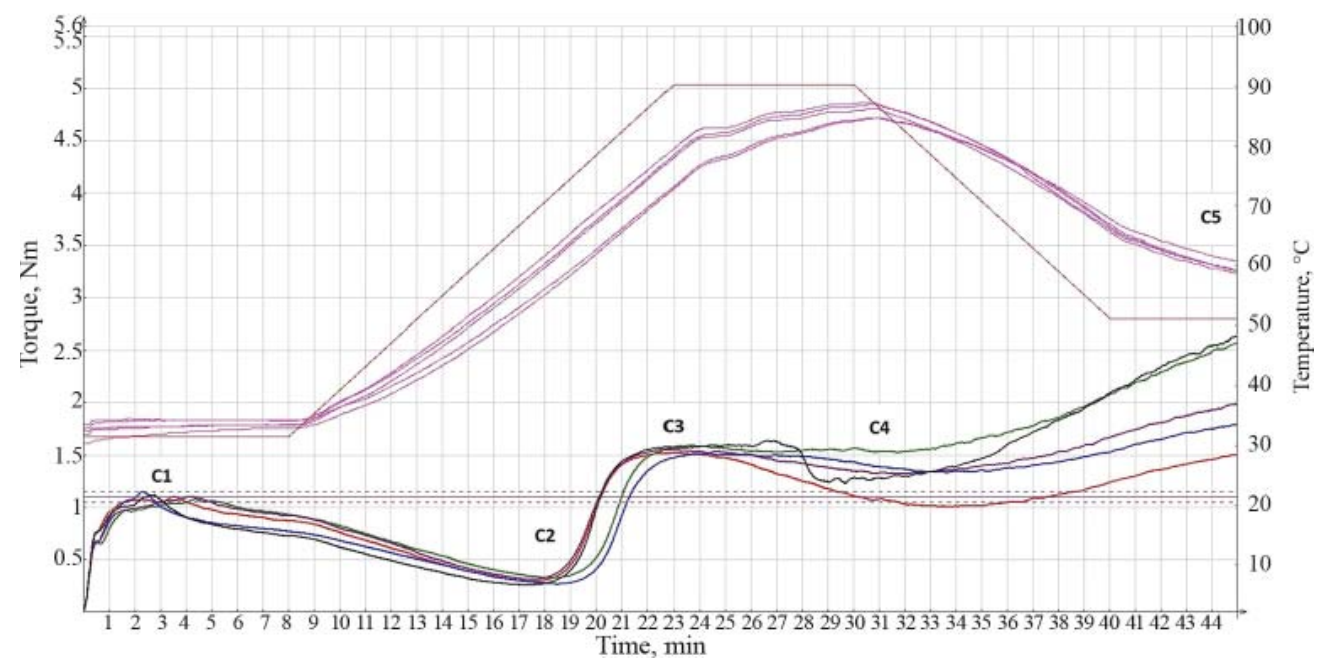

Fig. 1. Example of Mixolab curves of spelt cultivars -----: Altgold; -----: Rubiota; -----: Oberklumer Rotkorn; -----: Ostro; -----: Ebners Rotkorn

\section{Conclusions}

Results of the study indicated that Mixolab II can be used to predict the baking quality of $T r$. spelta and differentiate the genotype and climate conditions for quality characteristics. Genotypes and climatic factors affected the parameters related to the protein and starch properties of Mixolab II curves. Results indicated significant positive and negative correlations between Farinograph, Mixolab, and direct baking quality indicators. Strong correlation between Farinograph DS and C2 demonstrated the suitability of Mixolab II for bread making quality prediction of spelt flour. Slope $\alpha$ was also promising Mixolab parameter, showing the importance of protein weakening speed in estimation of direct baking parameter - bread volume of spelt, together with indirect baking quality indicator Zeleny test.

This research was supported by project ITEBIO "Support and innovations of special and organic products. Technologies for human healthy nutrition", ITMS: 26220220115 implemented under Operational Programme Research and Development. 


\section{References}

AACC International (2010): Approved methods of analysis, $11^{\text {th }}$ ed. AACCI Method 54-60.01, Determination of rheological behavior as a function of mixing and temperature increase in wheat flour and whole wheat meal by Mixolab, AACCI method 10-05.01, Guidelines for measurement of volume by rapeseed displacement, AACCI Method 56-81.03, Determination of falling number, St. Paul, MN, USA.

Abdel-Samie, M.A., Wan, J.J., Huang, W.N., Chung, K.O. \& Xu, B.C. (2010): Effects of cumin and ginger as antioxidants on dough mixing properties and cookie quality. Cereal Chem., 87, 456-460.

Arzani, A. \& Ashraf, M. (2017): Cultivated ancient wheats (Triticum spp.): A potential source of health-beneficial food products. Comp. Rev. Food Sci. F., 16, 477-488.

Békés, F., Ács, K., Gell, Gy., Lantos, Cs., Kovács, A-M., Birinyi, Zs. \& Pauk, J. (2017): Towards breeding less allergenic spelt-wheat with low FODMAP content - A review. Acta Alimentaria, 46, 246-258.

Bodroža-Solarov, M., Mastilović, J., Filipčev, B. \& Šimurina, O. (2009): Triticum aestivum spp. spelta - the potential for the organic wheat production. Prog. Theor. Exp. Phys., 13(2), 128-131.

Dhaka, V., Gulia, N. \& Khatkar, B.S. (2012): Application of Mixolab to assess the bread making quality of wheat varieties. Open Access Scientific Reports, 1, 183.

Dubat, A. (2010): A new AACC International approved method to measure rheological properties of a dough sample. Cereal Foods World, 55, 150-153.

ICC (2010): Standard Methods of the International Association for Cereal Chemistry. Method 116/1: Determination of the sedimentation value (according to Zeleny) as an approximate measure of baking quality, Method 131: Test baking of wheat flours, Method 155: Determination of wet gluten quantity and quality (Gluten Index acc. to Perten) of whole wheat meal and wheat flour (Tr. aestivum). International Association for Cereal Science and Technology, Vienna.

Kahraman, K., Sakiyan, O., Ozturk, S., Koksel, H., Sumnu, G. \& Dubat, A. (2008): Utilization of Mixolab to predict the suitability of flours in terms of cake quality. Eur. Food Res. Technol., 227, 565-570.

Koksel, H., Kahraman, K., Sanal, T., Ozay, D.S. \& Dubat, A. (2009): Potential utilization of Mixolab for quality evaluation of bread wheat genotypes. Cereal Chem., 86, 522-526.

Konvalina, P. (Ed.), BečKa, D., BečKovÁ, L., Capouchová, I., Dvořak, P. ... Urban, J. (2014): Pěstování vybraných plodin v ekologickém zemědělství. (Growing of non-traditional crops in ecological farming.) České Budějovice, ISBN 978-80-87510-32-2, 284 pages.

Kyptova, M., Konvalina, P. \& KhoA, T.D. (2017): Technological and sensory quality of grain and baking products from spelt wheat. Research for Rural Development. Agricultural Sciences, 2, 46-53.

Ozturk, S., Kahraman, K., Tiftik, B. \& Koksel, H. (2008): Predicting the cookie quality of flours by using Mixolab. Eur. Food Res. Technol., 227, 1549-1554.

Rachoń, L., Szumilo, G., Szafrańska, A. \& Kotyrba, D. (2016): Bread-making potential of selected spring wheat species depending on crop year and production technology intensity. Zemdirbyste - Agriculture, 103, 369376.

Schmiele, M., Ferrari Felisberto, M.H., Silva Clerici, M.T.P. \& Chang, Y.K. (2017): Mixolab for rheological evaluation of wheat flour partially replaced by soy protein hydrolysate and fructooligosaccharides for bread production. LWT - Food Sci. Technol., 76, 259-269.

Schober, T.J., Clarke, I. \& Kunn, M. (2002): Characterisation of functional properties of gluten proteins in spelt cultivars using rheological and quality factor measurements. Cereal Chem., 79, 408-417.

Švec, I. \& HRUŠKovÁ, M. (2018): Effect of golden and brown linseed fibre on wheat flour pasting, dough properties and bread quality. Cereal Res. Commun., 46(1), 114-123.

Wiwart, M., SzafrańsKa, A., WachowsKa, U. \& Suchowilska, E. (2017): Quality parameters and rheological dough properties of 15 spelt (Triticum spelta L.) varieties cultivated today. Cereal Chem., 94, 1037-1044. 